\title{
Una utopía artística: juego y televisión en Personalmente T.Video
}

\section{Artículo de investigación}

\section{Juan Carlos Guerrero-Hernández}

Investigador independiente

juan.guerrero.hernandez@gmail.com

Recibido: 25 de octubre de 2019

Aprobado: 27 de diciembre de 2019

Cómo citar este artículo: Guerrero-Hernández, Juan Carlos (2020). Una utopía artística: juego y televisión en Personalmente T.Video. Calle 14: revista de investigación en el campo del arte 15(28). pp. 368-381.

https://doi.org/10.14483/21450706.16278

\section{(a) (1)}

https://creativecommons.org/licenses/by/4.0/deed.es 


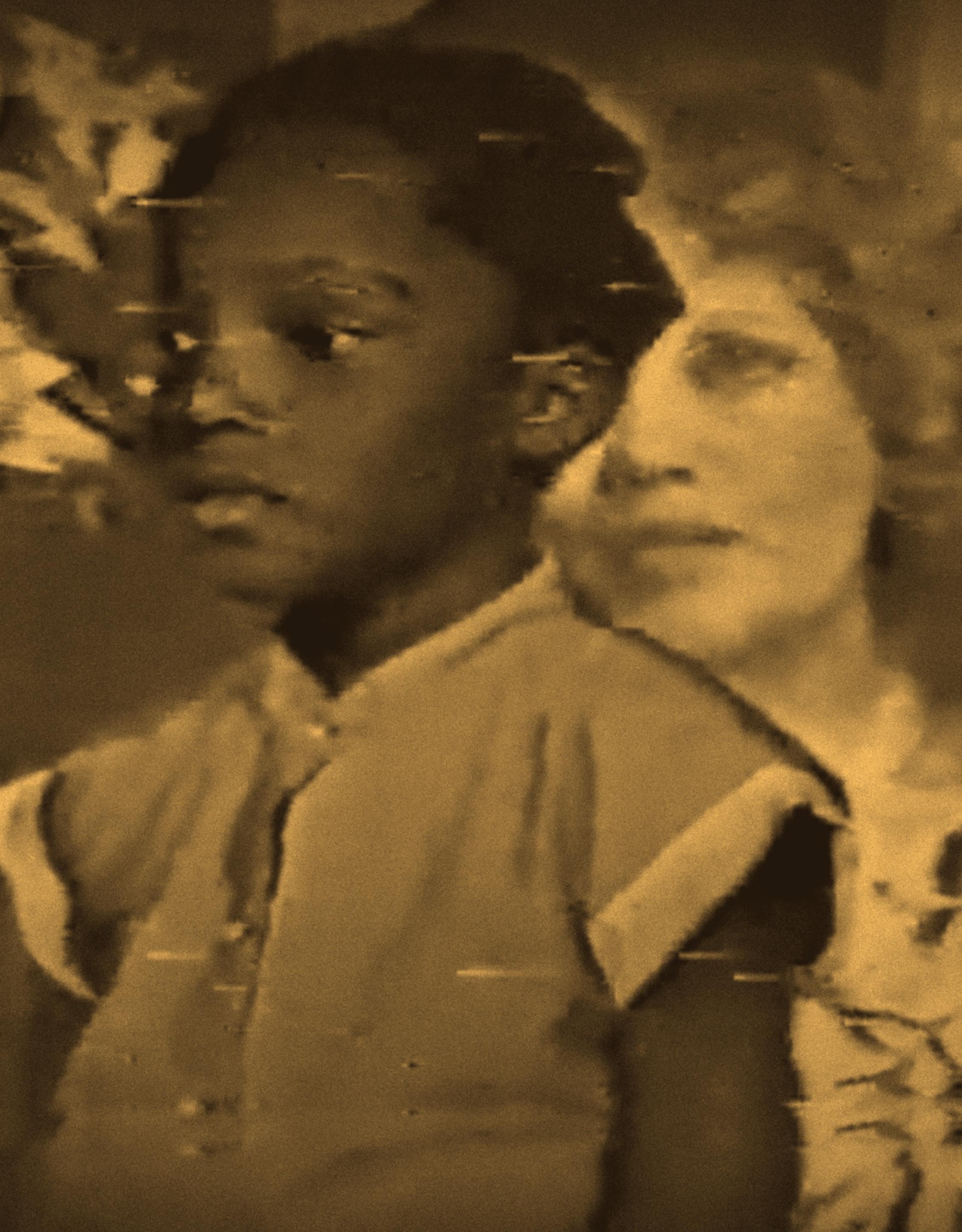


Una utopía artística: juego y televisión en Personalmente T.Video

\begin{abstract}
Resumen
Como aporte a los aún incipientes estudios de la televisión artística y del videoarte en Colombia en los años ochenta, se presenta un análisis del primer programa de televisión artística en el país. Este estudio de Personalmente T.Video (1986) identifica los retos que el programa se propuso de cara a la televisión institucional, el modo como asumió y exploró el flujo televisual y videístico en vínculo con el juego y apuesta por la educación libre de creación de nuevas imágenes y lenguajes televisivos. El estudio da cuenta de cómo los productores propusieron una utopía televisiva de corte pedagógico y lúdico en diálogo y contraposición con Roberto Rossellini, Jean-Luc Godard y Anne-Marie Miéville.
\end{abstract}

\title{
Palabras Clave
}

Juego; televisión; Colombia; tele-arte; videoarte; video comunitario.

An Artistic Utopia: Play and Television in Personalmente T. Video

\begin{abstract}
As a contribution to the still new study field of art television and video art in Colombia in the 1980s, we offer an analysis of the first art television program Colombia. This study of Personalmente T. Video (1986) identifies the challenges that the program set itself to achieve for institutional television, the way it assumed and explored television and video ebb and flow in connection with play and a commitment to free education for creating new images and television languages. The study shows how the producers proposed a television utopia of a pedagogical and playful nature in dialogue and contrast with Roberto Rossellini, Jean-Luc Godard and AnneMarie Miéville.
\end{abstract}

\section{Keywords}

Play; television; Colombia; art television; video art; community video.

Une utopie artistique : jeu et télévision en Personalmente T. Video

\section{Résumé}

En tant que contribution au champ d'étude encore nouveau de la télévision d'art et de l'art vidéo en Colombie dans les années 1980, nous proposons une analyse du premier programme de télévision d'art en Colombie. Cette étude de Personalmente T.Vidéo (1986) identifie les défis que le programme s'est fixé pour la télévision institutionnelle, la façon dont il a assumé et exploré les flux et reflux de la télévision et de la vidéo en relation avec le jeu et un engagement en faveur d'une éducation gratuite pour créer de nouvelles images et langages de télévision. L'étude montre comment les producteurs ont proposé une utopie télévisuelle à caractère pédagogique et ludique en dialogue et en contraste avec Roberto Rossellini, Jean-Luc Godard et Anne-Marie Miéville.

\section{Mots clés}

Jeu ; télévision ; Colombie ; télévision d'art ; art vidéo ; vidéo communautaire.

Uma utopia artística: jogo e televisão em Personalmente T. Video

\section{Resumo}

Como contribuição aos ainda incipientes estudos da televisão artística e do videoarte na Colômbia nos anos oitenta, se apresenta uma análise do primeiro programa de televisão artística no país até agora conhecido. Este estudo de Personalmente T.Video (1986) identifica que os 
desafios que o programa se propôs frente à televisão institucional, o modo como assumiu e explorou o fluxo televisual e de vídeo vinculado com o jogo e aposta pela educação livre de criação de novas imagens e linguagens televisivas. O estudo da conta de como os produtores propuseram uma utopia televisiva de natureza pedagógica e lúdica em dialogo e contraposição com Roberto Rossellini, Jean-Luc Godard e Anne- Marie Miéville.

\section{Palavras chave}

Jogo; Televisão; Colômbia; Tele arte; Videoarte; vídeo comunitário.

\section{Sug rurai mana apachiska pugllai kawachii nukatanta}

\section{Maillallachiska}

Kaipi niku mailla iachaikungapa kawachingapa Nukanchipa atun Ilagta Colombia suti,kai pusay watapi musuglla kawauringapa cha sallata sakingapa kunankama kai kallariska kai watapi atun warranya is kun pusay sugra chiuramanda kawachinkuna imamunaska, kai iachachii munaku Tukui kunata ningapa imasami kai runakuna ninaku Roberto Rosellini Jean-luc Gordad Chasallata AnneMarie Mieville.

\section{Rimangapa Ministidukuna}

Pugllai; kawachiku kawadiru; chasa suti llagta; ruraikuna kawachingapa; achea rurai. 


\section{Introducción ${ }^{1}$}

La historia de los medios en Colombia es aún un campo en formación (Gutiérrez, 2015) y muchos estudios son de corte 'presentista' y desconocen trayectorias (García y Barbosa, 2016). La situación en el campo de la historia del videoarte y de los experimentos de televisión artística es aún más desolador. El videoarte producido desde la segunda mitad de los años noventa ha recibido atención y se le ha discutido como si no tuviese precedentes en el país, como si no hubiese habido preguntas y cuestionamientos y trabajos locales que lo nutren desde incluso los años setenta. Es sintomático y preocupante que no existan estudios sobre la Bienal Internacional de Video-Arte (1986 -1992) organizada por el Museo de Arte Moderno de Medellín. En los últimos años ha habido exposiciones (que en muy pocos casos incluyen catálogos) interesadas en 'recuperar' la obra de los 'pioneros' que produjeron video desde los años setenta. Pero igualmente importante es reconocer que este interés parece obedecer más a la revaloración global del video que a un esfuerzo por hacer estudios históricos y críticos que presten atención a trayectorias locales y diálogos internacionales, a las operaciones conceptuales y plásticas en el que entonces era considerado localmente como un nuevo medio o relaciones que las obras establecen con otros medios como el cine y la televisión.

En el caso particular de la televisión experimental artística no existen estudios, con excepción de una tesis de maestría de Reynaldo Mejía, que asesoré y que junto con este artículo hacen parte del proyecto Génesis del video en Colombia que dirijo. La televisión experimental artística ha quedado relegada al olvido, en una tierra de nadie, porque los estudios de comunicación parecen no valorarla como producto cultural, los historiadores del cine y la televisión parecen verla como una expresión menor ('cosa de artistas'), y los historiadores del arte no suelen involucrar herramientas metodológicas y técnicas de televisión y cine.

Atendiendo a esta necesidad, el presente artículo es un pequeño primer aporte. Se analizará la obra que hasta el momento es la primera en haber sido producida para ser transmitida por televisión: Personalmente T.Video. Un programa de televisión. Este programa fue producido por Gilles Charalambos (1958-) y Pablo

1 Este artículo es resultado del proyecto de investigación 'Génesis del video en Colombia', apoyado por la Vicerrectoría de Investigaciones de la Universidad de Los Andes.
Ramírez (1964-2018), y transmitido por la Cadena 3 de Inravisión (hoy Señal Colombia) en $1986^{2}$. Es un programa complejo, de 21 minutos aproximadamente, y que, como la mayoría de videos de Charalambos, está compuesto por unidades diferenciadas o "semas", casi siempre definidos mediante el uso del 'corte directo'. Cada unidad establece posibilidades de sentido mediante referencias plásticas y conceptuales al cine y el video experimental, a la consideración crítica de referentes de la televisión en Colombia, etc. Cada unidad es creada con operaciones y procesamiento de la señal de video análogo. Para quienes estamos familiarizados con este tipo de edición no cuesta imaginarse las muchas horas de producción con los equipos de ese entonces.

Dada la complejidad del programa, el presente artículo hace una presentación parcial del análisis ya terminado y hecho a esta obra. Se ha optado por identificar algunos segmentos con los que se agrupan secuencias de unidades más importantes, a fin de dar cuenta, en este caso, cómo los productores se proponen una estructura tripartita para desarrollar un programa de tele-arte que se desmarque de la televisión institucional y presente una utopía de corte pedagógico y lúdico en diálogo y contraposición con Roberto Rossellini, Jean-Luc Godard y Anne-Marie Miéville. Se dejan por fuera las políticas públicas de la televisión nacional, los modelos pedagógicos empleados, el estudio de la obra desde del video arte, el arte por computador, y los videojuegos, la reformulación y subversión de los formatos televisivos, etc. El artículo se divide en tres partes que corresponden a tres momentos que el análisis ha identificado en el desarrollo de la propuesta utópica de tele-arte: (1) una formulación de la 'actitud' crítica y de apropiación de la historia de la televisión, (2) una presentación y formulación de estrategias lúdicas que habrían de liberar la imagen, producción y recepción televisiva, y (3) un reconocimiento de las posibilidades colectivas del telearte y apropiación creativa y social de la televisión. Debido al decaimiento del registro magnético y a problemas en el proceso de digitalización hecho antes del año 2012, las capturas no son buena calidad. Las cortas líneas blancas horizontales que se ven en las imágenes aquí insertadas no son originales del programa.
2 El programa está en youtube y por razones técnicas fue dividido en dos partes. Véase la primera parte de este programa en: https://www.youtube.com/watch?v=1YRQvF8nNX0 y la segunda parte en: https://www.youtube.com/watch?v=pjEac7cArWE ( $\mathrm{N}$ del ed.). 


\section{Collage y archivo-ología}

En la primera parte el segmento clave está conformado por una secuencia de ocho 'tomas' de archivo extraídas de transmisiones de televisión y obtenidas de Inravisión. La primera de ellas fue tomada de la primera transmisión de televisión desde la Luna (1969) que implicó una transformación radical en los imaginarios del mundo, del arte, y de la imagen; transformación atesorada en los manifiestos del Espacialismo que abogaron por un "arte espacial" que pasara de "la tela, el bronce", etc. a la "pura imagen aérea" y "suspendida" (Fontana et al., 1988a), y a la imagen electromagnética propia de un arte "liberado" (Fontana et al., 1988b). A esta 'toma' le suceden otras extraídas de documentales o de documentos noticiosos. Por ejemplo, vemos imágenes documentales del asesinato de John F. Kennedy (1963) con sonido del documental televisivo y con un filtro sepia que da un toque nostálgico. Luego siguen: la coronación de Luz Marina Zuluaga como reina universal de la belleza (1957), con sonido diegético de la transmisión; la primera visita y misa de un papa en tierras colombianas (1968) con ruido eléctrico extradiegético; el gol (acompañado del mismo sonido que la 'toma' anterior) con que la selección nacional ganó a Paraguay en Bogotá en la Copa América de 1975 y con el fue considerada la "revelación" del torneo aunque no obstante perdió la final contra Perú; una entrevista realizada a la vidente y revelación política Regina 11 (entre 1982 y 1985) en la que ella afirma que toda persona puede ser vidente y puede pronosticar el futuro de eventos mundiales como ella misma dice haber hecho con la tragedia de Armero; cortes de noticieros colombianos registrando y hablando sobre la toma del Palacio de Justicia; y cortes de noticieros colombianos registrando y hablando de la tragedia de Armero (1985) (Mejía, 2018, p. 36).

Lo que está en juego no es solo el uso y compilación de imágenes de archivo televisivo (algo ya hecho por el "cine de compilación"), y en este caso de 'hitos' de la televisión colombiana. También cuenta la manera como está construida la secuencia audiovisual. Por ejemplo, las seis últimas 'tomas' cubren un espectro de lo que podría describirse como 'obras mayores' de los géneros 'tele-dramáticos' del teleteatro y el teledrama tan apreciados en el país hasta los años setenta. En efecto, no sin ironía, se va de la comedia -en la transición de la coronación de la Miss Universo al papa (Imagen 1)—, al drama tragicómico —en la transición entre la revelación futbolística a la revelación política y mistérica- y a la tragedia, en la transición de la tragedia política y

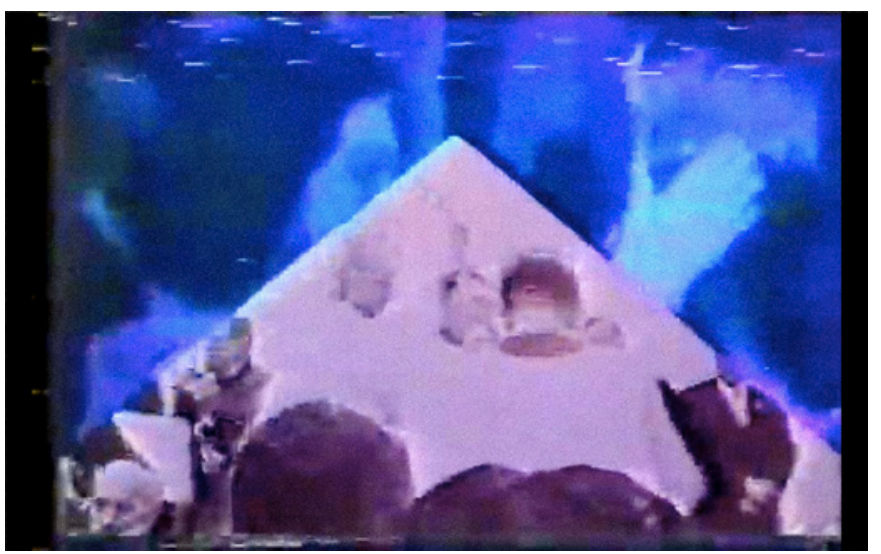

Imagen 1. Personalmente T.Video (Charalambos y Ramírez, 1986). Video, color, sonido, 21'.

militar a la tragedia política y natural. Pero igualmente estas transiciones temáticas contrastan con otras capas de sentido sugeridas, por ejemplo, por la relación y la discrepancia auditiva entre 'tomas' o entre audio e imagen. Hay entonces un "collage" que introduce una subversión en la compilación y desafía la naturaleza representativa o literal de las imágenes (Wees, 1993, p. 84), abriendo un rico espectro de posibilidades interpretativas distintas a las usuales en televisión.

Igualmente importante es que la secuencia ha sido montada y editada usando sencillas transiciones con wipe, que al decir de la época era un proceso "propio" al medio eléctrico del video y la televisión, y era un modo de operación de la señal eléctrica que, no obstante, ya resultaba "obsoleto" para entonces (Charalambos y Ramírez, 1987, p. 112). Con estas operaciones, como diría Eugeni Bonet, se ha de reconocer que si bien es cierto que "en los medios electrónicos (vídeo, televisión, infografía) se puede encontrar [...] una concepción similar de collage" cinematográfico, los efectos y recursos técnicos ofrecen "cualidades bien distintas" (2014, p. 142), y llevan las marcas de su realidad medial y mediática que es central en Personalmente T.Video, y que este se encarga de explotar en la segunda y tercera partes.

Y finalmente, además de la compilación y la construcción de collages de imágenes, la obra involucra el no menos relevante hecho de tomar imágenes transmitidas que no solo tienen una fuerza histórica y cultural, sino que además han sido originalmente ensambladas en y para la comunicación noticiosa globalizada de los años ochenta (y en vínculo con el auge de las antenas parabólicas y las conexiones por satélite). Personalmente T.Video las recicla y des-ensambla, o para decirlo 
empleando los términos de la época, se apropia de ellas en tanto que no solo 'cita la historia', sino también el medio televisivo (Wees, 1993, p. 45).

En este sentido, es necesario subrayar que el tono histórico de la secuencia de las ocho 'tomas' radica tanto en la compilación de imágenes de archivo televisivo, como en la evocación y collage de temas y géneros históricos de narración televisiva, y en la apropiación de los procesos históricos de edición en televisión. Es decir, se trataba tanto de los contenidos como del modo de enunciarlos (-ology) material y narrativamente. Por esto mismo, esta secuencia plantea lo que llamo una archivo-ología. Esta noción parcialmente evoca la idea de la archiveology inicialmente esbozada por Joel Katz en 1991 al comentar Dal Polo all'Equatore (1987) de Yervant Gianikian y Angela Ricci Lucchi (posiblemente la primera película experimental que explícitamente trabajó con material de archivo cinematográfico), y posteriormente retomada por Catherine Russell para hablar de cine digital (2018, p. 22). No obstante, en lo que concierne a la televisión, y en especial a Personalmente T.Video, llamo archivo-ología al hacer (los griegos dirían techné) orientado a potenciar o generar un conocimiento sobre cómo se nos ha representado y puede ser representada una historia televisualmente, y cómo esas representaciones que son históricas en sí mismas tienen una potencialidad pedagógica y tele-artística.

Pedagógica, como veremos, en tanto que se orienta al conocimiento, revisión de contenidos y apropiación participativa de cómo la enunciación material y narrativa televisual tienen lugar. Tele-artística porque, como se mostrará, apunta y abre la posibilidad de una articulación artística del medio, procesos, lenguajes, y contenidos televisuales que obviamente no se limita al mero uso por parte de un artista trabajando en televisión (vg. el programa The Medium is The Medium (1969) producido por Fred Barzik para la WGBH-TV en Boston), ni simplemente a la transmisión de arte por televisión (vg. el programa "Land At" (1969) de Gerry Schum para la Sender Freies Berlin/ARD).

En este orden de ideas, antes de entrar en materia, es inevitable reconocer que Personalmente T.Video no es ajeno a algunas ideas que Rossellini expuso en su ensayo Utopía, autopsia: 10 a la 10 (1974). Allí el italiano expresó la necesidad de transformar la televisión que se había han alejado de su "función como servicio hacia el individuo para ponerse al servicio de una entelequia abstracta y uniformizadora [sic] como es el concepto de masa" (Quintana, 2013, p. 71). Rossellini abogaba por un retorno a la televisión educativa y cultural guiada por la tradición cinematográfica y la necesidad de "examinar un nuevo abecedario de las imágenes". Decía, igualmente, que se llegaría a la utopía y a que todos supiéramos ver con nuestros ojos (porque ver es saber) mediante un ejercicio de autopsia ("ver con los propios ojos") que permitiera "recrear y volver a experimentar la historia [casi que] desde el principio para que conduzca, aunque sea imaginariamente, a un final diferente" (Cramer, 2017, p. 78). Este interés ya lo venía desarrollando en biografías realizadas para televisión, entre ellas Socrate (1970), y Cartesius (1973), y la famosa serie televisiva La lotta dell'uomo per la sua sopravvivenza (o 'La lucha del hombre por su supervivencia') producida entre 1967 y 1969, en la que siguió un orden cronológico y discutió relaciones entre la ciencia, el arte y las sociedades humanas, desde los etruscos hasta la llegada a la Luna.

No es casual que la primera toma de la compilación en Personalmente T.Video sea la llegada a la Luna. Mientras que Rossellini, en un tono reminiscente de la idea del cine como arte total, quiere abarcar toda la historia del arte y la cultura occidental, y asume la televisión como "arte sin tradiciones" (en Bazin, 1995, p. 94), Charalambos y Ramírez se interesan en la televisión y reconocen su tradición. Mientras el italiano busca alcanzar un nuevo comienzo, Personalmente T.Video se interesa por una práctica archivo-ológica que abre espacios de posibilidad de enseñanza y desarrollo de una televisión artística o tele-arte.

\section{Autopsia y tele-juego}

La segunda parte del video involucra varios segmentos de los que analizaré cinco clave, que permiten mostrar cómo Personalmente T.Video hizo una 'autopsia' que perfila, desnuda, radicaliza o subvierte ciertos elementos formales y reglas de comunicación televisiva para permitir al público "ver con los propios ojos" algunas posibilidades pedagógicas y artísticas de la televisión. El primer segmento muestra en un plano general lateral y toma fija a una niña (en adelante 'niña $A^{\prime}$ ) viendo televisión en una sala. En ese televisor vemos esa imagen repetida porque la cámara está conectada a su televisor en retroalimentación (Imagen 2). Luego la niña gira cuerpo hacia la cámara, dice "estoy en la televisión", y camina directo hacia la cámara hasta cubrir el lente con su cuerpo. Luego, en la pantalla en negro aparece el texto: “... O ESTÁ LA TELEVISIÓN EN TI?”. 


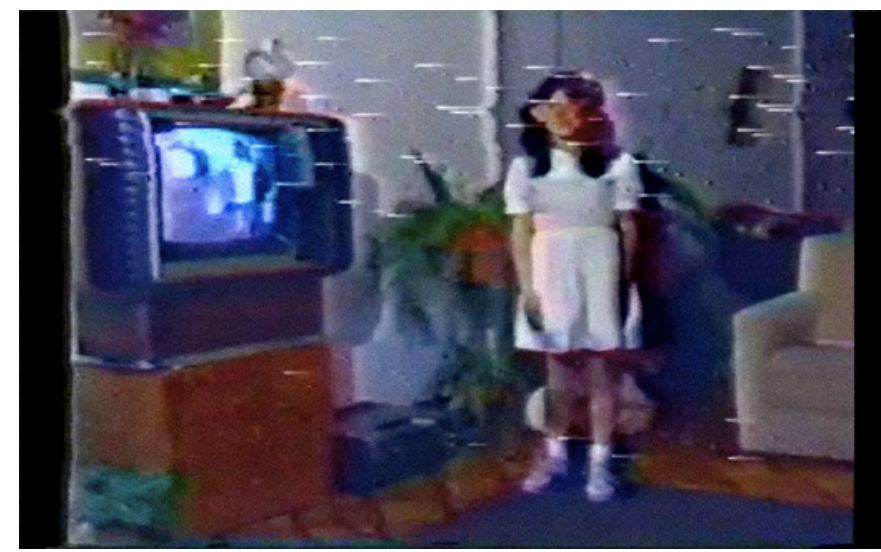

Imagen 2. Personalmente T.Video (Charalambos y Ramírez, 1986). Video, color, sonido, 21'.

Al decir "estoy en la televisión" la niña apunta a un anidamiento y desdoblamiento. Desde el punto de vista del televidente ella parece afirmar lo obvio, es decir, que está en nuestro espacio televisivo, en nuestra televisión. Pero desde su punto de vista, y gracias a una 'anamorfosis' visual producida por la retroalimentación en sesgo, ella se ha visto siendo vista. Su enunciado afirma que ella se ve en el espacio televisivo del televidente, y que ha cumplido, por así decirlo, su deseo de ser representada en la imagen televisiva. Luego, al desplazarse a la cámara y cubrir el lente por completo, hace desaparecer el espacio televisivo y fuerza al televidente a 'salir' al espacio televisual (i.e., el espacio de recepción), revelando la actitud receptora del televidente y su deseo de involucrarse con la imagen televisual. Entre este desear verse en la imagen y desear con la imagen, se anuncia un desdoblamiento de los espacios psicológicos de la imagen de televisión.

El "...O" en pantalla, además de sugerir el desdoblamiento (más que una disyunción exclusiva), es una elipsis literal-visual que sirve de transición al siguiente segmento que abre con una toma de la niña alejándose de la cámara (aunque seguida en un travelling in) dentro un estudio de televisión, y acercándose a un televisor. Con esta toma pareciera como si la niña regresara al espacio televisivo del televidente, y como si, hasta cierto punto, la acompañáramos en su regreso. Cuando ella llega al televisor, el televidente nota que aquel transmite la imagen la imagen de la niña al lado suyo en retroalimentación. Ella procede a mover la antena en la que hay (esto no lo sabe el televidente) un desmagnetizador que con el movimiento produce "anamorfismos visuales de la imagen" (Charalambos y Ramírez, 1987, p. 117). Este uso de desmagnetizador es a todas luces reminiscente de obras iconoclastas y altamente lúdicas de Nam June Paik, por ejemplo su TV Nixon (1965), que con gesto parcialmente brechtiano están interesadas en modular la imagen y sugerir la re-elaboración lúdica del deseo del espectador, así como su mediación activa y crítica.

Al respecto no sobra recordar que el también influyente director y productor de televisión Jean-Christophe Averty, a quien Charalambos también renocía como referente de la televisión francesa, usó el juego (especialmente con cromakey) a fin de "descretinar" la televisión en los sesenta y setenta (Plas, 2016, p. 161), y a fin de tratar de encontrar espacios de libertad de creación y participación para un público más amplio que el de técnicos, directores y operarios. Paik y Averty trabajaron con cadenas de televisión pública y entendieron que los juegos son, pedagógicamente hablando, procesos de re-elaboración simbólica (creación de algo nuevo o de un nuevo sentido), "procesos de proyección (diferentes objetos y situaciones sobre los que se busca investir de un mismo sentido primordial)", y "procesos de reiteración de sistemas de creencias y a la vez destructores de los mismos" (López y García, 2014, p. 32). Los juegos despliegan la capacidad de soñar que involucra elementos de realidad e incluso preparan para la realidad (Sahovaler, 2009, p. 120).

Charalambos y Ramírez retoman los juegos de Paik y Averty para plantear una reformulación crítica de la televisión en términos de una programación lúdica cercana a lo que llamaré tele-juego. Con este término no nombro el género de juegos en televisión. Me refiero, de manera más básica y abierta, a un despliegue conjunto del juego de imágenes y personajes en la imagen televisiva, el juego de artistas y personajes con la imagen televisiva, y el juego de la imagen televisiva y electromagnética. Este triple juego tiene lugar en muchos segmentos de la segunda parte, en los que se evidencia, entre otras cosas, que los artistas buscaron "sobreutilizar" la consola y probar todas sus posibilidades. ${ }^{3}$

Es en este contexto del tele-juego que tiene lugar toda la segunda parte de la obra. Así, un tercer segmento muestra la pantalla dividida en dos (Imagen 3). En la mitad izquierda se ve a una niña (en adelante 'niña B') cargando una cámara que ella mece en sus brazos como si fuese una muñeca. En la otra mitad están las imágenes que esa cámara registra. Este segmento no solo sugiere el uso personal y la cercanía física y afectiva con la cámara. También invita a considerar que en Conversación con Gilles Charalambos, Bogotá, 5 Julio de 2017. 


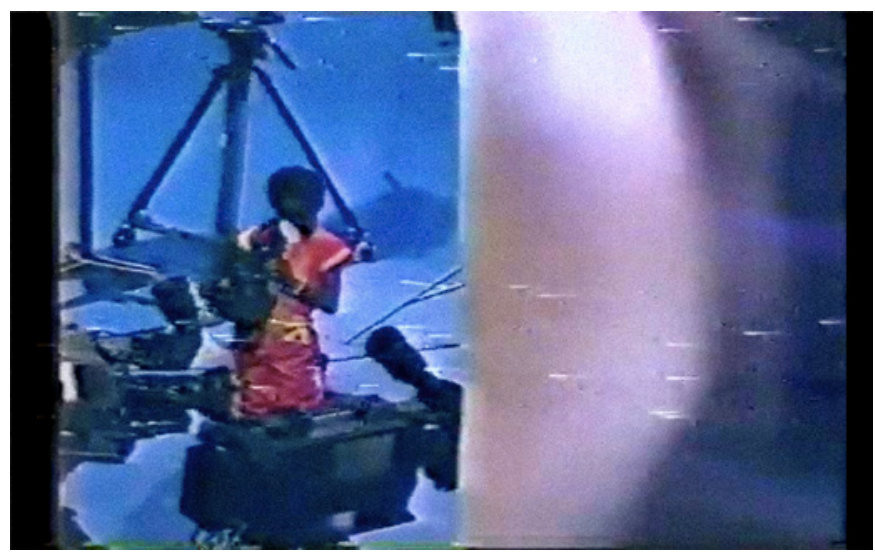

Imagen 3. Personalmente T.Video (Charalambos y Ramírez, 1986). Video, color, sonido, 21'

el juego la cámara y el registro son, como diría Donald Winnicot, objetos y fenómenos transicionales que forman la base de procesos creativos y de transformación y de relación entre la niña y el mundo circundante $(2003,32)$. Por su parte, el cuarto segmento a incluir muestra, primero, un plano muy largo, y luego un plano completo (ambos reminiscentes del género documental tipo 'cámara escondida') de la 'niña A' llegando a la puerta principal de Inravisión, e infructuosamente tratando de convencer al celador y a un policía para que la dejen entrar. Mientras tanto se la escucha decir en voz en off: "¿Quiere hacer televisión? El Estado es el único dueño de nuestros canales radioléctricos de transmisión de televisión. Nadie puede transmitir una señal de televisión sin pasar por el Estado". Más adelante la misma niña pregunta: "¿Dónde está la libertad de emisión, e información y expresión?"

El quinto segmento es una entrevista hecha por la 'niña A' a Fernando González Pacheco, quien no solo era presentador sino también productor de televisión. Editada en blanco y negro y de baja calidad, la entrevista fue realizada siguiendo convenciones como la lateralidad del entrevistador y el uso de cámara fija. No obstante, estas convenciones se rompen cuando la entrevistadora mantiene los ojos cerrados mientras su entrevistado responde tres preguntas aparentemente ingenuas: "¿Qué quisiera hacer usted en televisión", "¿Por qué no hace esto en televisión", "¿Para usted qué es la televisión?". El orden de las preguntas termina por revelar y forzar contradicciones, predictibilidad y superficialidad de las reflexiones de Pacheco sobre qué sea la televisión. Adicionalmente, en la posproducción se intervinieron las entrevistas insertando un cuadro y un círculo de la misma imagen original colorizada, con los que refuerzan la idea del juego y juguetonamente

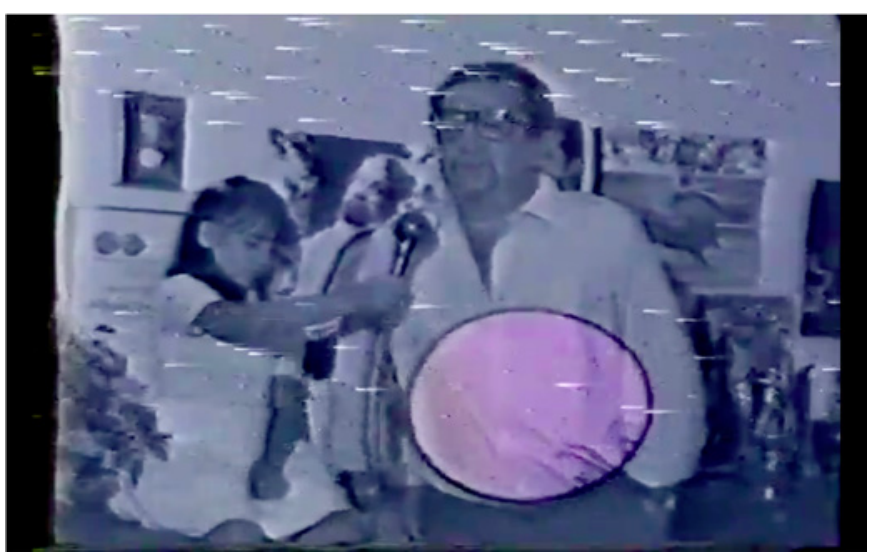

Imagen 4. Personalmente T.Video (Charalambos y Ramírez, 1986). Video, color, sonido, 21'.

comentan la entrevista. Para el televidente es muy fácil creer que quien está haciendo esta manipulación e inserción de la imagen es la 'niña B', quien pocos minutos antes de la entrevista fue mostrada sentada frente a la consola master, ponchando imágenes mediante wipes con la imagen suya que la cámara registraba en retroalimentación y en sesgo.

Este segmento de la entrevista hace eco de lo que Godard propuso en su Six fois deux/Sur et sous la communication de 1976: interrogar las imágenes, sonidos y textos sobre sus interrelaciones (2010, p. 90), y contraponer, por un lado, las imágenes, sonidos y textos que se ajustan a significaciones dominantes o consignas establecidas, y por otro, las "justamente imágenes", sonidos y textos que "implican un devenir presente, un tartamudeo" que cabe expresarme mejor a modo de preguntas que semejan bloquear el paso a la respuesta (Deleuze, 1995, p. 39). En este segmento, las imágenes justas y las justamente imágenes se contraponen y combinan en la que parece ser una farsa que además de 'rellenar' (farcire) con formas en color imágenes y discursos de baja calidad, se venga juguetonamente de la realidad ideológica de la institución de la televisión colombiana (Imagen 4).

Hay suficientes elementos para reconocer que esta segunda parte del programa dialoga con "La radio libre", ese proyecto de cortometraje escrito hacia 1977 y que Felix Guattari esperaba producir en video para recrear la irrupción de Radio Alice en el monopolio estatal de comunicación en 1976. Este proyecto tendría como protagonistas a Elena y a su acompañante esquizoide, Ugo (Guattari, 2012). Una de las cuestiones clave de este proyecto es la resonancia que Guattari planteó entre la mente de Ugo y Radio Alice (recreada 
como Radio Galaxie), de manera que la radio libre no reconoce un límite preciso entre emisor y receptor, y aglutina tipos distintos de discursos que los canales institucionales separaban $(2012,15)$. Estas cuestiones resuenan en Personalmente T.Video, que echó mano de diversos elementos, lenguajes, y géneros televisivos (vg. la cámara escondida, la entrevista, el programa infantil, etc.), los aglutinó y canibalizó mediante el juego, conel que logró cierta dinámica de producción 'esquizoide' de flujos no codificados, y de fluctuaciones de la señal y de un género al otro que debilitan cada género. Tampoco se puede minimizar el movimiento 'esquizoide', ese juguetón vaivén entre 'niña A' y 'niña B', entre en el espacio en la imagen televisiva y el espacio de deseo y fascinación con la imagen televisiva, entre el espacio físico, psicológico y el ideológico de recepción y el de producción de dicha imagen, entre la ficción ilusoria y la ficción creativa y crítica.

Personalmente T.Video apostó por una televisión libre, una televisión que además de mostrar y jugar con el nuevo "abecedario" de las imágenes televisivas y jugar con contenidos, materiales y formas narrativas de la televisión, asumiera el tele-juego como lugar en y desde el cual elaborar y experimentar la televisión con distancia brechtiana y bajo la estructura abierta godardiana. Como sucede con obras producidas en los años ochenta por la famosa videoartista británica Dara Birnbaum, y que Charalambos muy posiblemente conoció al vivir en Inglaterra a comienzos de esa década, Personalmente T.Video se concentró en "las convenciones específicas y los géneros de la televisión" para proponer una mezcla de géneros con la que "el aparato total de la tecnología de la televisión y las maquinaciones de sus convenciones se vuelven legibles como instrumentos de ideología en el lenguaje visual" y como estructuras "que determinan la experiencia perceptiva colectiva" e individual (Buchloh, 1982, p. 54). Ahora bien, Birnbaum define "el lenguaje del videoarte en relación con la institución de la televisión de manera [similar a como otros artistas...] habían definido el lenguaje de la pintura y la escultura en relación con la institución del museo". Su crítica institucional sigue anclada al espacio de la galería mediante estrategias heredadas del minimalismo. Por su parte, Personalmente T.Video no solo se salió del ámbito tradicional de la obra de arte al ser una obra-programa de tele-arte. También asumió la necesidad de 'emular' a Rossellini y Godard en el sentido de que si estos pasaron del cine a la televisión como un modo de crítica a y distanciamiento de la 'moribunda' institución del cine de la época, Charalambos y Ramírez, como veremos a continuación, criticaron la 'moribunda' institución del arte y de la televisión institucional, y se formularon la posibilidad de dar un doble paso fuera de ambos ámbitos.

\section{Utopía, televisión y video}

La tercera parte abre con una secuencia cargada de ironía y humor. Comienza con una toma de la 'niña B' como televidente que elige los contenidos. Ella sostiene en su mano un casete de betamax y se dirige a la cámara mientras dice "este es un poquito de videoarte colombiano". Luego hay un medio primer plano del televisor. Sobre su pantalla, y mediante el uso de disolvencia, se ha sobrepuesto el cabezote de un video hecho por Charalambos y Édgar Acevedo en 1984. Mientras el video se reproduce 'dentro' de la pantalla, el uso de wipe permite que emerjan cuatro franjas negras verticales como si el televisor y el video quedaran encerrados detrás de una reja (Imagen 5).

Luego se pasa a una toma larga que muestra, no sin ironía y humor y doble sentido, en plano medio y casi a la misma altura —en la pantalla - en la que estaba el televisor, el cuadro Policarpa Salavarrieta camino del suplicio (1825) de la colección del Museo Nacional. Inmediatamente la cámara hace un lento paneo hacia la izquierda, y aparece -incrustado mediante sobreposición con wipe y compresión como se hizo al inicio de esta secuencia - un cuadro móvil de similar tamaño al del cuadro de la heroína, que contiene una secuencia de bailarines tomada de Global Groove (1973) de Paik. La cámara continúa el paneo registrando pinturas colombianas de siglo XIX constreñidas por los marcos en que los exhibe el Museo Nacional, mientras que el cuadro incrustado comienza a danzar en la pantalla tan libremente como lo hacen los cuerpos de las bailarinas.

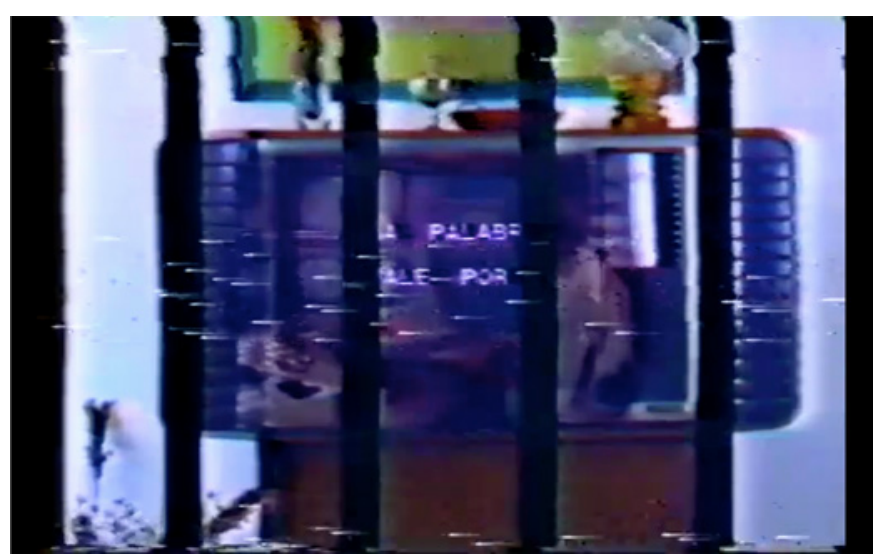

Imagen 5. Personalmente T.Video (Charalambos y Ramírez, 1986). Video, color, sonido, 21'. 
Este segmento ironizaba la marginalización que hasta el momento sufría el videoarte colombiano ignorado por el boom de la pintura de la mano del narcotráfico, o vilipendiado por los discursos críticos y prácticas artísticas que aún seguían estando bajo la sombra protectora y promotora de Marta Traba, quien en palabras de Jonier Marín, había reaccionado enconadamente "contra las vanguardias del momento" a las que calificaba de "'tonterías', 'pretensión (sic) tecnológica', etc.". Según Marín, ella creía que "el quietismo y el atraso [eran...] ventajosas cualidades del arte nacional" (Marín, 1974). En este sentido es pertinente recordar que el mismo año de la realización de Personalmente T.Video, el Museo Nacional alojó el XXIX Salón Nacional de Artes Visuales y la gran retrospectiva de Alejandro Obregón, artista que, como es conocido, fue muy promocionado por Traba. Igualmente significativo es que mientras un un columnista comparó la obra reciente de Obregón con un 'enlatado' televisivo porque repetía fórmulas de 20 años atrás (Caballero, 1985), Ana María Escallón criticó el nivel del Salón, quejándose de que los medios de comunicación no informan acerca de la cultura, no dedican tiempo a la discusión creativa, y los artistas no ayudan con su respectiva pasividad (1985, p. 219).

Personalmente T.Video aceptó el reto de 'tomarse' la televisión con un programa tele-artístico que no se interesara en informar o en instruir en un arte ya canonizado y legitimado por la historia. En este sentido no podía ser más grande la distancia entre este programa y el programa Historia del arte moderno contada desde Bogotá (1983-84), presentado por Traba y caracterizado por su estructura de comunicación y conocimiento unidireccional, vertical, tradicional y conservador, aún dirigido a la élite cultural. Por su parte, Personalmente T.Video, en tanto programa de corte tele-artístico, abogó por tomarse en serio el juego y por plantear la televisión como posibilidad de salir de la museizante institución de la historia del arte. Pero esa salida significaba en su momento desprenderse de la institución de la televisión a la que el formato del programa de Traba seguía igualmente abocado.

En esta dirección se ha de entender otro segmento de esta tercera parte en el que vemos un grupo reunido frente a un televisor, conversando sobre el proceso de capacitación en recreación y el trabajo colectivo que se venía desarrollando en el barrio la Perseverancia, con el fin de educar a los niños y fortalecer lazos entre los vecinos del barrio. Lo que ellos veían en el televisor era el registro de actividades de recreación que había previamente desarrollado y grabado con una cámara conseguida por intermedio de Socorro Ramírez. Fue ella quien al llegar al barrio a comienzos de los años setenta a trabajar como profesora, ${ }^{4}$ introdujo estrategias y actividades pedagógicas en la comunidad, y posteriormente, con apoyos de embajadas, obtuvo equipos de video para desarrollar "video comunitario" o televisión comunitaria con sistemas de video de pequeño formato.

El video comunitario se mostraba como una posibilidad pertinente para una televisión libre en la que el juego con trucos básicos de producción de las imágenes, contenidos, materiales y formas narrativas de televisión, y el juego desarrollado en colectivo permitiera y nutriera la participación y la construcción colectiva, y permitiera vislumbrar posibilidades de tele-arte y apropiación creativa y social de la televisión. Y esto era tanto o más apremiante cuando para 1986, a menos de un año de su fundación y bajo el falso argumento de que hacer televisión comunitaria era muy costoso, Teleantioquia fue rápidamente controlada por la politiquería, intereses privados y una élite interesada en difundir "imágenes de región que solo responden a los intereses de unos pocos" (García, 2012, p. 70). Contrario al caso colombiano, en otros países como Canadá — cuyo video comunitario fue presentado en 1985 en los Museos de Arte Moderno de Bogotá y Medellín por Andreé Duchaine (De Villa, 1985) —, se desarrolló libremente como televisión de acceso comunitario, horizontal, descentralizada y bidireccional (Goldberg, 1990, p. 6) bajo los auspicios de la Oficina Nacional de Cine de Canadá y la televisión pública (Boyle, 1997, p. 32).

Evidentemente esas circunstancias institucionales no dejaban de ser distintas a las nuestras. No obstante, como respuesta al argumento de "no hay plata para eso", un segmento final muestra en un plano holandés (que sugiere inestabilidad y dinamismo) a Charalambos y Ramírez sosteniendo espejos en sus manos y reflejando su entorno y la cámara mientras conversan sobre el proceso de producción del programa. A pesar de las dificultades y limitaciones, el programa era evidencia de la viabilidad del proyecto de video comunitario y de una televisión diferente. De hecho, los créditos del programa dan a conocer que la producción costó 140.000 pesos colombianos (700 USD de entonces). A diferencia de los altos costos de posproducción del cine auspiciado por FOCINE y el mercado del arte apoyado por Colcultura y fuentes 'non sanctas', el video arte y el video comunitario se imaginaron en ese momento como 'espacios'

En conversación con Socorro Ramírez, Bogotá, 12 de noviembre de 2017. 
muchos más económicos y pertinentes para un trabajo artístico y televisivo de relevancia pedagógica y diálogo, participación y construcción. En este sentido el título Personalmente T.Video cabría interpretarse como una transición del individuo que hace la autopsia al trabajo colectivo de participación y diálogo. ¿Qué hubiera sido del video arte y del video comunitario en Colombia si FOCINE, COLCULTURA e Inravisión (que para entonces estaba entrando en el proceso de privatización de dos canales) hubieran asumido el reto que Charalambos y Ramírez propusieron?

\section{Consideraciones finales}

Personalmente T.Video radicalizó la reflexión que Raymond Williams (1975) hizo diez años antes. En vez de denunciar el carácter ideológico de la TV como lo hizo la crítica marxista en la Revista Alternativa (López, 2012), de celebrar el melodrama como lo hizo la escuela de Jesús Martín-Barbero, influyente en la segunda mitad de los ochenta, o de usar la televisión como promoción de un discurso o de una élite cultural como fue el caso de Traba, Personalmente T.Video adoptó y subvirtió convenciones y géneros a fin de identificar lúdicamente otras posibilidades y estrategias artísticas de la televisión como flujo informático que produce contenido, nuevos lenguajes, crítica, y recepción. Personalmente T.Video figuró la posibilidad de crear programas de arte en el doble sentido del genitivo.

Decía antes que este proyecto recuerda a Rossellini. Queda claro que sus diferencias son mucho mayores. El italiano trabajó con una televisión que aún no se había transformado en esa caracterizada por la guerra por la audiencia y definida por los intereses de las empresas. Además, Rossellini seguía anclado en la tradición cultural de élite, como lo evidencian sus series biográficas sobre genios de la cultura occidental en las que las referencias teatrales en la puesta en escena son sorprendentes. Su proyecto asumía las posibilidades pedagógicas en términos de la representación y la instrucción. Por su parte, Charalambos y Ramírez inicialmente apostaron por la televisión pública y de hecho lograron transmitir su trabajo, y en el proceso de producción, confirmaron la posibilidad de desarrollar una televisión diferente en una apuesta comunal, con medios y formatos accesibles. A diferencia de Rossellini, Charalambos y Ramírez exploraron el flujo televisivo y optaron por el juego libre y plural de construcción de nuevas imágenes, de unidades de sentido, y de lenguajes.
A pesar del ánimo con que cierra el programa, Charalambos y Ramírez no continuaron con el ambicioso proyecto. Si bien los costos de producción no eran altos, sí eran significativos para dos jóvenes recién graduados, y cuando el acceso a ciertos equipos de edición seguía estando obstaculizado por los altos costos o por las limitaciones de horas de uso de equipos bajo control de agencias de publicidad, universidades, y noticieros con los que ellos pudieran hacer intercambios. Inravisión no estuvo interesada en permitir la retransmisión del programa. El formato inusual del programa muy posiblemente fue considerado subversivo. Podemos sospechar que, en este sentido, después de ese rechazo por parte de Inravisión, Charalambos y Ramírez sintieron lo mismo que Godard y Miéville sintieron con su Six fois deux: una nueva televisión y comunicación podría "demostrarse bajo condiciones controladas como un experimento, pero nunca tendrán éxito en el mundo exterior" porque las instituciones políticas y mediáticas no lo permitirán (Cramer, 2017, p. 156). De hecho, Personalmente T.Video tuvo que esperar dos años para ser transmitido por segunda y última vez a las 10 p.m. en el programa Una mirada a Francia en la cadena tres, auspiciado por la embajada francesa: programa en el que Charalambos presentó ejemplos de video arte producido por franceses y colombianos.

A diferencia de Godard y Miéville que en Six fois deux seguían anclados a la figura del director/a, Charalambos y Ramírez dieron reconocimiento al video comunitario como posibilidad de una televisión horizontal con la cual "radicalizar las actitudes populares hacia la televisión" (Sterritt, 1999, p. 251), radicalizar el deseo de estar en ella (como lo enunciara la 'niña B'), de ver en ella, y de jugar con ella (como objeto y como medio, etc.). Radicalizar esas actitudes empujaría al límite las capacidades y potencialidades pedagógicas y tele-artísticas de la televisión. A diferencia de Rossellini, Godard y Miéville, Personalmente T.Video vislumbraron una salida comunitaria para la televisión fuera de la televisión institucional. Pero este era también un proyecto artístico de fuerte carácter utópico que como otros proyectos de Godard vieron pronto su fin. No así el video comunitario que continuó por unos años en la Perseverancia y continúa en otros barrios de Bogotá y de otras ciudades, y que es igualmente digno de serle reconocida su historia. Por cierto, ¿es el caso de la Perseverancia el primero en nuestro país?

A pesar de todo, las utopías dejan su 'estela', bien sea porque después de muchos años alimentan otras, o porque inevitablemente resuenan con proyectos que se 
preguntan por posibilidades similares, aunque renuncien a establecer nuevos lenguajes $u$ opten por matizar las actitudes populares del público. En este sentido, y solo a manera de abrebocas, puede decirse que con el primer programa hasta ahora documentado de tele-arte en Colombia dialogan dos producciones. La primera es la exploración plástica titulada Escenarios de un diálogo (1988) de José Manuel Valdéz y Óscar Potes de la cual se produjeron dos partes de las tres planeadas. Ellas han sido recuperadas recientemente y serán discutidas en otro lugar. Elementos de aquella utopía, en este caso de tomo más godardiano, pueden identificarse en Ojo y Vista: peligra la vida del artista (1988) de Luis Ospina, programa-documental del cual también hablaré en otro lugar, y que fue producido como piloto para el espacio documental Rostros y Rastros de Óscar Campos y la Universidad del Valle. Por último, no sobra recordar que, en 1995, en el marco de la I Bienal del Barrio Venecia, Charalambos y Roberto Sarmiento reformularon la apuesta utópica de 1986 con el proyecto TV Necia, en el que usaron la televisión comunal del barrio. De hecho, dado que Charalambos fue profesor de tantos estudiantes de Cine y televisión en la Universidad Nacional, y sabiendo que su programa fue también presentado en Alemania y Argentina, no debería sorprender encontrar otros 'rastros' de y diálogos con su proyecto de 1986.

Como se hace evidente, hay muchos análisis por hacer e historias por contar sobre los cruces de video, televisión y arte. No son una tarea que puedan hacer pocos ni desde una sola 'disciplina' o un lugar. Sea este artículo mi invitación a trabajar trabajar en grupo para contarlas.

\section{Referencias}

Bazin, A. (1995). “Cinema and Television”, en Adriano Aprà (ed.), My Method. New York: Marsilio.

Bonet, E. (2014). Escritos de vista y oído. Barcelona: MACBA

Boyle, D. (1997). Subject to Change: Guerrilla Television Revisited. New York: Oxford University Press.

Buchloh, B. H. D. (1982). "Allegorical Procedures: Appropriation and Montage in Contemporary Art", en Art Forum 21(1).

Caballero, A. (1985). “Obregón, del sancocho al enlatado", en Semana. Disponibles en: https://www.semana.com/cultura/articulo/ del-sancocho-al-enlatado/7056-3

Charalambos, G. y Ramírez, P. (1987). “Personalmente T-Video. Un proceso de comunicación artística". Tesis de pregrado, Universidad Javeriana. Bogotá.

Cramer, M. (2017). Utopian Television: Rossellini, Watkins, and Godard Beyond Cinema. Minneapolis: University of Minnesota Press.

De Villa, O. (1985). “El video gana espacios en el medio de la imagen", en El Colombiano, 31 de enero.

Deleuze, G. (1995). "Three Questions on Six Times Two", en Deleuze, G. Negotiations 1972 -1990. New York:

Columbia University Press.

Escallón, A. (1985). “El arte en Bogotá Réquiem para el Salón de Artistas", en El Espectador, 4 de octubre.

Fontana, L., Joppolo, B., Kaisserlian, G., Milani, M. (1986a). "Primo manifesto dello Spazialismo, redatto nel magggio 1947", en Enrico Crispolti (ed.) Lucio Fontana, Catalogo generale. Milán: Electa.

Fontana, L., Milani, M., Joppolo, B., Burri, A. (1986b). "Manifesto del movimento spaziale per la televisione, 17 maggio 1952", en Enrico Crispolti (ed.) Lucio Fontana, Catalogo generale. Milán: Electa.

García, D. (2012). “Breve historia de la televisión regional en Colombia", en Revista Latinoamericana de Ciencias de la Comunicación 9(6).

García, D. y Marialva, C. (2016). "Historias de la televisión en Colombia: vacíos y desafíos". Comunicación y sociedad 26.

Godard, J. (2010). Pensar entre imágenes. Conversaciones, entrevistas presentaciones y otros fragmentos. Barcelona: Intermedio editores.

Goldberg, K. (1990). The Barefoot Channel: Community Television as a Tool for Social Change. Vancouver: New Star Books.

Guattari, F. (2012). A Love of UIQ. Minneapolis: Univocal. Gutiérrez, E. (2015). “Entradas y claves para la historia de la televisión en Colombia", en José Miguel Pereira (ed.), Televisión y construcción de lo público. Bogotá: Universidad Javeriana. 
López, F. (2012). La ficción y la información noticiosa televisivas de los años 70 a través del prisma de la Revista “Alternativa. Folios 27: 139-159.

López, B. y García, R. (2014). “El juego de la ilusión y la ilusión del juego: el diseño (con)sentido". Taller Servicio 24 Horas 10(19).

Marín, J. (1974). "Marta Traba y la Retaguardia" en El Tiempo. Lecturas Dominicales, 11 de Agosto.

Mejía Barrera, R. (2018). "El videoarte colombiano en los años ochenta y sus tensiones con la televisión". Tesis de maestría, Maestría en Historia del Arte, Universidad de Los Andes, Bogotá. Disponible en: https://tinyurl.com/y5z44522

Plas, M. (2016). “Les utopies électroniques de Paik et d'Averty: investigations et expérimentations télévisuelles", en Cinémas 26 (2-3). https://doi.org/10.7202/1039370ar

Quintana, A. (2013). "Pensar la utopía de la televisión en un mundo sin utopías", en Jorge La Ferla (comp.) Televisiones. Buenos Aires: Espacios Fundación telefónica.

Russelll, C. (2018). Archiveology: Walter Benjamin and Archival Film Practices. Durham: Duke University Press. https://doi.org/10.1215/9780822372004
Sahovaler, D. (2009). El sujeto escondido en la realidad virtual: de la represión del deseo a la pornografía del goce. Buenos Aires: Letra Viva.

Sterritt, D. (1967) Seeing the Invisible: The Films of Jean-Luc Godard. Cambridge: Cambridge University Press.

Valderrama, C. (2009). La investigación en medios de comunicación en Colombia 1980-2009, en Nómadas 31: 362-376.

Wees, W. (1993). Recycled Images: The Art and Politics of Found Footage Films. New York: Anthology Film Archives New York City.

Williams, R. (1975). Television: Technology and cultural form. London: Schocken Books.

https://doi.org/10.4324/9780203450277_chapter_2 https://doi.org/10.4324/9780203450277_chapter_5 https://doi.org/10.4324/9780203450277_chapter_1 https://doi.org/10.4324/9780203450277_chapter_6 https://doi.org/10.4324/9780203450277_chapter_3 https://doi.org/10.4324/9780203450277_chapter_4

Winnicot, D. (2003). Realidad y Juego, traducción Floreal Mazía. Barcelona: Editorial Gedisa. 